\title{
Short-term benefit of neoadjuvant hormone therapy in patients with localized high-risk or limited progressive prostate cancer
}

This article was published in the following Dove Press journal: Cancer Management and Research

\author{
Bing-Lei Ma ${ }^{1,2, *}$ \\ Lin Yao ${ }^{1,2, *}$ \\ Yu Fan ${ }^{1,2}$ \\ Yu Wang ${ }^{1,2}$ \\ Yi-Sen Meng ${ }^{1,2}$ \\ Qian Zhang ${ }^{1,2}$ \\ Zhi-Song $\mathrm{He}^{\mathrm{l}, 2}$ \\ Jie Jin ${ }^{1,2}$ \\ Li-Qun Zhou ${ }^{1,2}$ \\ 'Department of Urology, Peking \\ University First Hospital, Institute of \\ Urology, Peking University, Beijing, \\ People's Republic of China; ${ }^{2}$ Beijing Key \\ Laboratory of Urogenital Diseases \\ (male), Molecular Diagnosis and \\ Treatment Center, Beijing, People's \\ Republic of China \\ *These authors contributed equally to \\ this work
}

Correspondence: Qian Zhang; Yi-Sen Meng

Department of Urology, Peking University First Hospital, Institute of Urology, Peking University, No. 8 Xishiku Street, Beijing I00034, People's Republic of China Tel +86I 3910970928 ;

+86 I34 66660291

Email zhangqianbjmu@I26.com; mgyss@163.com
Purpose: Radical surgery is the preferred method for local high-risk and limited progressive prostate cancer in the routine clinical setting. However, current guidelines do not recommend neoadjuvant hormone therapy (NHT). Opinions regarding NHT vary among individual clinicians. According to the experience gained at our center, we explored the benefits of NHT for patients with prostate cancer during the perioperative period in this study.

Methods: In this retrospective study, we explored the perioperative benefits of NHT among 189 patients with local high-risk or limited progressive prostate cancer who underwent radical prostatectomy and divided them into two groups: the NHT group and the non-NHT group. The NHT regimens were a gonadotropin-releasing hormone $(\mathrm{GnRH})$ agonist alone (3.75/11.25 mg of leuprolide or $3.6 / 10.8 \mathrm{mg}$ of goserelin acetate), an androgen receptor antagonist (ARA) alone, or a combination of the two. The duration of treatment was $<3$ months, 3 to 6 months, or $>6$ months.

Results: We found that NHT could reduce the surgery time and intraoperative hemorrhage, thus reducing the difficulty of surgery; NHT could also improve the postoperative recovery of patients. However, it did not reduce the stage of prostate cancer or positive surgical margin rate. Conclusions: Neoadjuvant therapy is optional for some patients. We believe that NHT will improve the overall prognosis of patients as progress continues in the medical field in the future. Keywords: localized high-risk, limited advanced, prostate cancer, neoadjuvant hormone therapy, short-term benefit

\section{Introduction}

With the development and progress of medicine, more and more patients with prostate cancer are found through prostate-specific antigen (PSA) screening. For local high-risk prostate cancer (clinical stage of T1 or T2 with a PSA level $>20 \mathrm{ng} / \mathrm{mL}$ or Gleason score $>7$ ) and limited progressive prostate cancer (clinical stage $\geq \mathrm{T} 3$ ), ${ }^{1}$ radical surgery is the preferred method of treatment in the routine clinical setting.

In our center, from January 2013 to December 2017, 1,071 cases of radical prostatectomy were performed. There were 663 cases of localized high-risk and local progression, accounting for $61.9 \%$ of the total number of operations. Neoadjuvant hormone therapy (NHT) is an important method to treat with localized high-risk and locally advanced prostate cancer in our hospital. Of the 565 patients who underwent prostate biopsy and radical surgery in our center, 139 received NHT, which account for $25.0 \%$. 
Although guidelines for treatment of prostate cancer have been updated, $\mathrm{NHT}^{2-4}$ was still not recommended. Some studies have shown that NHT cannot improve the patients' prognosis and that it may interfere with postoperative pathological stages. ${ }^{5-8}$ However, some clinicians have insisted that NHT is associated with a decreased rate of stage pT3 cancer (downstaging), a decreased positive surgical margin (PSM) rate, and a lower incidence of positive lymph nodes. ${ }^{9}$ Therefore, according to the experience gained at our center, we explored the benefits of NHT for patients with prostate cancer during the perioperative period.

\section{Materials and methods}

\section{Patient population}

We reviewed the clinical and pathological records of 189 patients (with complete medical records) with local highrisk or limited progressive prostate cancer who underwent radical prostatectomy at Peking University First Hospital from January 2013 to December 2017. Of these patients, 116 received NHT (NHT group) and 73 did not (non-NHT group). The NHT regimens were a gonadotropin-releasing hormone (GnRH) agonist alone (3.75/11.25 mg of leuprolide or 3.6/10.8 $\mathrm{mg}$ of goserelin acetate), an androgen receptor antagonist (ARA) alone, or a combination of the two. The duration of treatment was $<3$ months, 3-6 months, or $>6$ months.

Several factors were assessed: age, height, weight, body mass index, prostate volume before NHT, preoperative prostate volume, diabetes, history of abdominal or pelvic surgery, choice of NHT, treatment time, PSA level before biopsy, preoperative PSA level, Gleason score, operative time (OT), estimated blood loss (EBL), clinical stage, pathological stage, PSM rate, hospital length of stay (LOS), and drainage duration (DD). The patients' baseline characteristics and perioperative data are shown in Table 1.

All patients were followed up for 12-60 months (median duration was 26 months). All patients were informed in detail, and approved for being recruited as subjects for scientific purposes during postoperative telephone followup. All patients provided oral informed consent over phone for being part of the retrospective study. The study was accepted and approved by the Biomedical Research Ethics Committee of Peking University First Hospital.

\section{Statistical analysis}

Continuous parametric variables are presented as mean \pm standard deviation, and continuous nonparametric variables are presented as median and interquartile range. Analysis of variance and the Kruskal-Wallis test were used to evaluate the relationships of perioperative data between the two groups. Pearson's chi-square test was used to compare the PSM rate and positive rate of lymph node dissection. For all statistical analyses, a two-sided $p$-value of $<0.05$ was considered statistically significant. All data were analyzed by SPSS version 24.0 (IBM Corp., Armonk, NY, USA).

\section{Results}

The data analyzed in the NHT group are shown in Table 2. Five treatment options were available for all 116 patients: (1) an ARA alone for $\leq 3$ months ( $\mathrm{n}=32$ ), (2) a GnRH agonist alone for $\leq 3$ months $(n=3)$, (3) a combination of these two agents for $\leq 3$ months ( $n=52$ ), (4) a combination of these two agents for 3-6 months $(n=20)$, (5) and a combination of these two agents for $>6$ months $(n=9)$. We compared the change in the PSA level and prostate volume (before biopsy versus preoperatively) to evaluate the influence of NHT on the PSA level and prostate volume. The statistical analysis showed that few patients chose treatment with a GnRH agonist alone $(n=3)$; therefore, we focused on the other four groups. In all patients receiving NHT, the PSA level and prostate volume were significantly reduced. Moreover, the reductions in the PSA level and prostate volume in patients treated with an ARA alone were lower than those in patients who underwent combination treatment, and the magnitude of the reduction was associated with the duration of treatment. (Figure 1).

We also compared the differences in the clinical stage and pathological stage to verify whether NHT can reduce the stage of prostate cancer. (Figure 2) We found that the postoperative pathological stage of localized prostate cancer might advance despite treatment with NHT. Therefore, we cannot conclude that NHT can reduce the stage of prostate cancer.

We further explored the role of age in the efficacy of neoadjuvant endocrine therapy. Patients were divided into three layers according to age: aged $\leq 60$ years old, $61-$ 70 years old, and $>70$ years old. The comparison of clinical staging and pathological staging in these three patients was similar to the general trend, which further demonstrated that neoadjuvant endocrine therapy could not reduce the final pathological staging. (Figures 3-5)

Finally, we compared the OT, EBL, PSM rate, LOS, and DD between the NHT and non-NHT groups to explore 
Table I Summary of overall data

\begin{tabular}{|c|c|c|c|}
\hline Factors & NHT Group $(n=\mid 16)$ & Non-NHT Group $(n=73)$ & p-value \\
\hline Age $(y)$ & $66.6(\mathrm{SD} \pm 7.0)$ & $66.0(\mathrm{SD} \pm 7.2)$ & $0.718 *$ \\
\hline Height (m) & I.70 (IQR: I.67-I.74) & I.70 (IQR: I.67-I.76) & $0.274 \#$ \\
\hline Weight $(\mathrm{kg})$ & $71.0(S D \pm 10.1)$ & $71.4(\mathrm{SD} \pm 9.6)$ & $0.802 *$ \\
\hline BMI $\left(\mathrm{kg} / \mathrm{m}^{2}\right)$ & $24.50(\mathrm{SD} \pm 2.90)$ & $24.32(\mathrm{SD} \pm 2.77)$ & $0.783 *$ \\
\hline Volume of Prostate before NHT & 46.45 (IQR: 33.95-65.12) & l & 1 \\
\hline Preoperative Volume & 31.50 (IQR: 22.25-46.15) & 32.09 (IQR: 24.50-42.95) & $0.629 \#$ \\
\hline Diabetes & $19(16.4 \%)$ & II (I5.1\%) & $0.810 ※$ \\
\hline History of Abdominal or Pelvic Surgery & $22(19.0 \%)$ & $2(2.7 \%)$ & $0.001 ※$ \\
\hline \multicolumn{4}{|l|}{ Choice of NHT } \\
\hline ARA alone & $32(27.6 \%)$ & l & l \\
\hline $\mathrm{GnRH}$ agonist alone & $3(2.6 \%)$ & l & l \\
\hline Combination & $81(69.8 \%)$ & l & I \\
\hline \multicolumn{4}{|l|}{ Treatment Time of NHT } \\
\hline$\leq 3$ months & $87(75.0 \%)$ & l & I \\
\hline $3-6$ months & $20(17.2 \%)$ & l & I \\
\hline$>6$ months & $9(7.8 \%)$ & I & I \\
\hline PSA before Biopsy & I9.96 (IQR: II.86-33.25) & l & I \\
\hline Preoperative PSA & 2.69 (IQR: 0.65-6.73) & I7.60 (IQR: 8.60-24.22) & $0.00 \mathrm{I} \#$ \\
\hline Gleason Score & $7.09(\mathrm{SD} \pm 1.95)$ & $7.63(\mathrm{SD} \pm 1.34)$ & $0.994 *$ \\
\hline OT (min) & 109.0 (IQR: 7I.3-I44.8) & 109.0 (IQR: 7I.5-|8I.5) & $0.616 \#$ \\
\hline $\mathrm{EBL}(\mathrm{mL})$ & 35.0 (IQR: 20.0-100.0) & 70.0 (IQR: 20.0-I50.0) & $0.005 \#$ \\
\hline \multicolumn{4}{|l|}{ Clinical Staging } \\
\hline TI & II (9.5\%) & $2(2.7 \%)$ & $0.075 \%$ \\
\hline $\mathrm{T} 2$ & $72(62.1 \%)$ & $28(38.4 \%)$ & $0.001 ※$ \\
\hline T3a & 9 (7.8\%) & $32(43.8 \%)$ & $0.001 ※$ \\
\hline $\mathrm{T} 3 \mathrm{~b}$ & $19(16.4 \%)$ & II (I5.I\%) & $0.001 ※$ \\
\hline $\mathrm{T} 4$ & $5(4.3 \%)$ & 0 & $0.001 \%$ \\
\hline \multicolumn{4}{|l|}{ Pathological Staging } \\
\hline T0 & $4(3.4 \%)$ & 0 & $0.001 ※$ \\
\hline $\mathrm{T} 2$ & 55 (47.4\%) & 17 (23.3\%) & $0.001 \%$ \\
\hline T3a & $21(18.1 \%)$ & $27(37.0 \%)$ & $0.004 \%$ \\
\hline $\mathrm{T} 3 \mathrm{~b}$ & $34(29.3 \%)$ & $29(39.7 \%)$ & $0.139 \%$ \\
\hline $\mathrm{T} 4$ & $2(1.7 \%)$ & 0 & $0.001 ※$ \\
\hline PSM rate & $31.0 \%(36 / 116)$ & $28.8 \%(2 \mathrm{I} / 73)$ & $0.741 ※$ \\
\hline $\operatorname{LOS}(d)$ & 4 (IQR: 4-6) & 5 (IQR: 4-6) & $0.094 \#$ \\
\hline $\mathrm{DD}(\mathrm{d})$ & 3 (IQR: 3-4) & 4 (IQR: 3-4) & $0.122 \#$ \\
\hline
\end{tabular}

Notes: *Analysis of variance, \# the Kruskal-Wallis test, ※ Pearson's chi-square test.

Abbreviations: BMI, body mass index; PSA, prostate specific antigen; NHT, neoadjuvant hormone therapy; ARA, androgen receptor antagonists; OT, operative time; EBL, estimated blood loss; PSM, positive surgical margins; LOS, hospital length of stay; DD, drainage duration.

the short-term benefits of NHT for patients with prostate cancer. (Table 3) The data showed that among the above parameters, OT, EBL, LOS, and DD were significantly different between the NHT and non-NHT groups. The OT of combination treatment for $\leq 3$ months $(p=0.04)$ and $>6$ months $(p=0.039)$, the EBL of combination treatment for $\leq 3$ months $(p=0.001)$, the LOS of combination treatment for 3-6 months $(p=0.016)$, and the DD of combination treatment for 3-6 months $(p=0.007)$ in the NHT group were significantly different from those in the non-NHT group. However, there was no significant difference in the PSM rate between the NHT and non-NHT groups $(p=0.132)$.

All patients were followed up for 12-60 months (median duration was 26 months). Of the 189 patients, 32 developed metastases, mainly to bone (19 cases), 


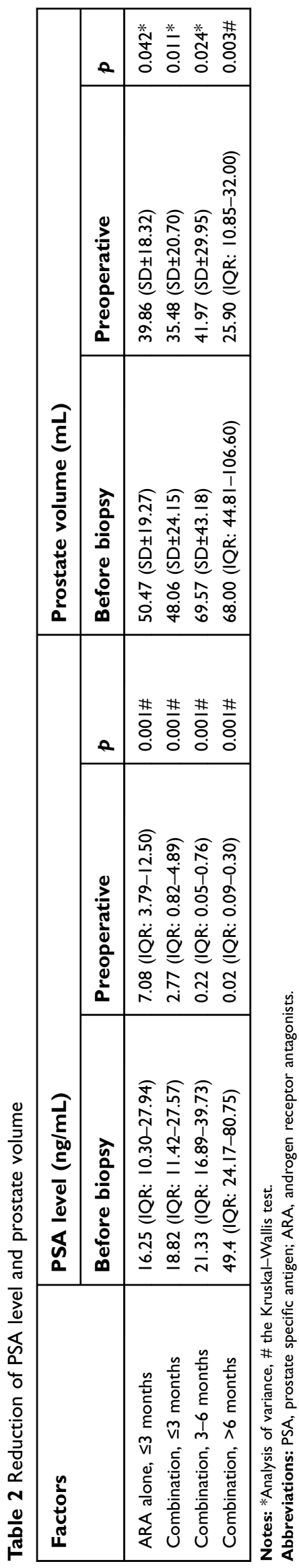

pelvic lymph node ( 7 cases), and lung ( 6 cases). Among the 32 patients with metastasis, 18 patients were in the NHT group and 14 patients in the non-NHT group, which showed no statistical difference $(p>0.05)$. Further analysis revealed that 24 out of 32 patients had clinical staging $\geq \mathrm{T} 3 \mathrm{~b}$, so we concluded that postoperative metastasis of prostate cancer was not significantly correlated with NHT, but was significantly correlated with clinical staging.

\section{Discussion}

NHT for patients is still not recommended in various guidelines because it does not significantly improve the patients' prognosis. ${ }^{2-4}$ However, regardless of its effects on prognosis, we should pay attention to the short-term effects of NHT on patients during the perioperative period. In the 2018 EAU guideline, ${ }^{3}$ NHT was thought to be associated with a tumor downstaging, a decreased positive surgical margin (PSM) rate, and a lower incidence of positive lymph nodes. ${ }^{9}$ We also conducted a series of studies to explore the benefits of NHT for prostate cancer patients, but we came to a different conclusion. In our study, NHT could reduce surgical bleeding, shorten operation time, and help patients with postoperative recovery. However, it couldn't reduce tumor staging and the PSM rate.

Different doctors have different subjective feelings about the effect of NHT on the difficulty of surgery. Some doctors believe that NHT leads to greater adhesion and edema in the pelvic area, which would make separation and other operations more difficult, thus prolonging the OT and increasing the difficulty and risk of surgery. In the present study, however, NHT could reduce the OT and risk of intraoperative bleeding, thus reducing the difficulty of surgery. Endocrine therapy works by inhibiting synthesis of testosterone and dihydrotestosterone, thereby restraining the growth of the gland, shrinking the prostate volume, and reducing the blood supply. Although pelvic adhesion can become aggravated and tissue separation can become more difficult after NHT, the aggravation of adhesion might have less impact on the difficulty of surgery. Therefore, in general, the application of NHT before surgery shortened the OT and reduced intraoperative hemorrhage in the present study. In addition, patients who received NHT had early extubation and early discharge after surgery. With the extensive application of the concept of Enhanced Recovery After Surgery, the effect of NHT on patients' postoperative recovery is also worth considering. 


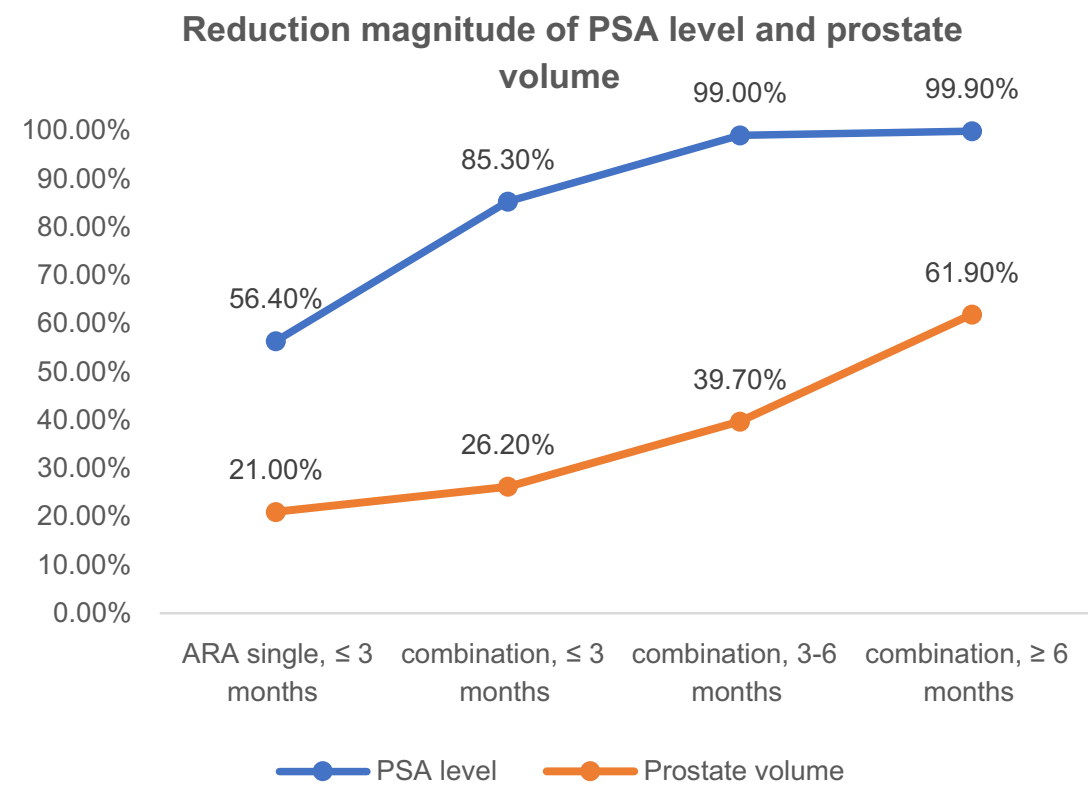

Figure I Reduction magnitude of PSA level and prostate volume.

\section{Change of clinical and pathological stage}

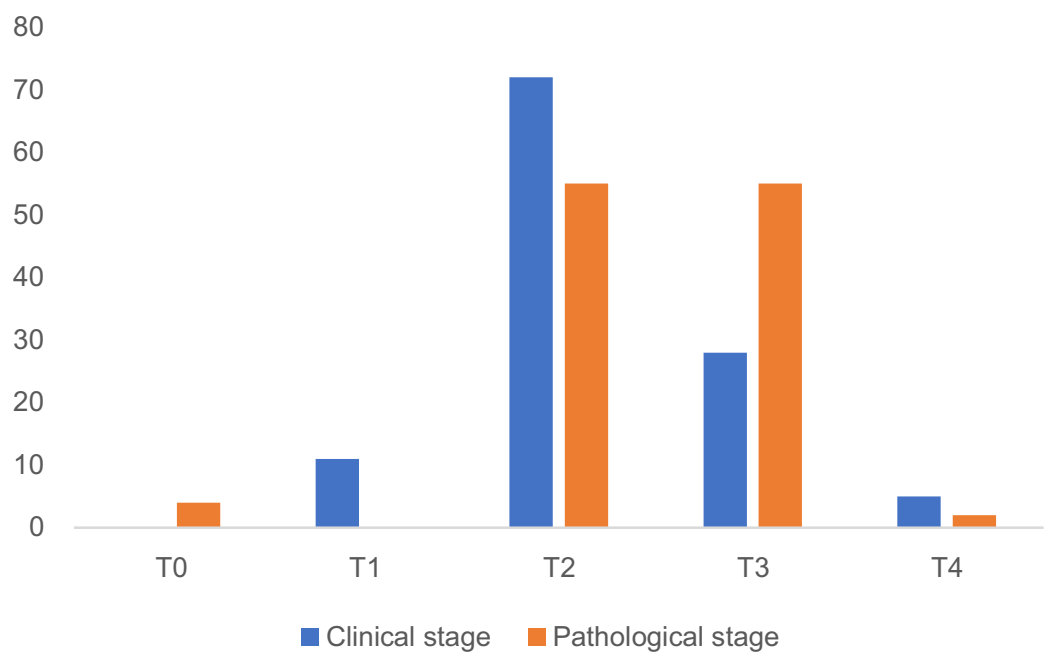

Figure 2 Change of clinical and pathological stage.

The role of NHT in reducing the clinical stage of prostate cancer and the PSM rate is controversial. To some extent, these two possible effects of NHT are the reasons why some doctors choose to treat patients with hormone therapy before surgery, especially for patients with locally advanced prostate cancer, prostate cancer with lymph node metastasis, or even prostate cancer with oligopoly metastasis. ${ }^{3,9}$ Nevertheless, our data show that the effect of NHT was not significant in reducing either the clinical stage or PSM rate in the present study. On the one hand, these results might be related to the inability of preoperative pelvic MRI to accurately assess the clinical staging of patients, or to the shorter duration of NHT in patients. However, on the other hand, the mechanism of hormone therapy for prostate cancer involves inhibition of the synthesis of testosterone and dihydrotestosterone and the activity of androgens, thus achieving the purpose of treating prostate cancer. Unlike chemotherapy, hormone therapy cannot kill tumor cells directly. Therefore, in patients with advanced prostate cancer or oligopoly 


\section{Change of clinical and pathological stage (age $\leq 60)$}

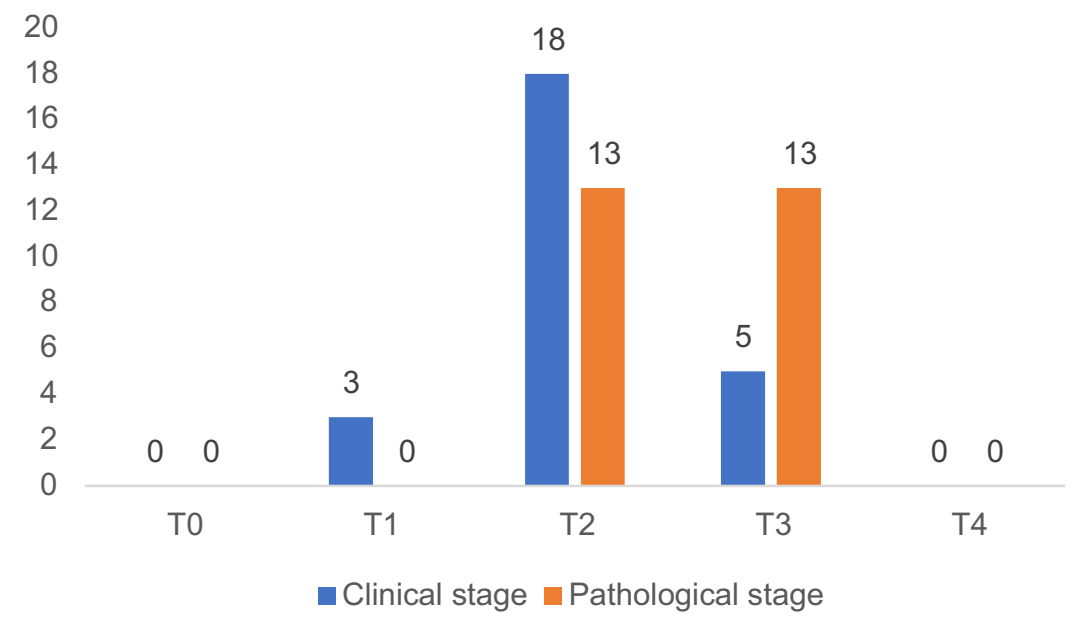

Figure 3 Change of clinical and pathological stage (age $\leq 60$ yea).

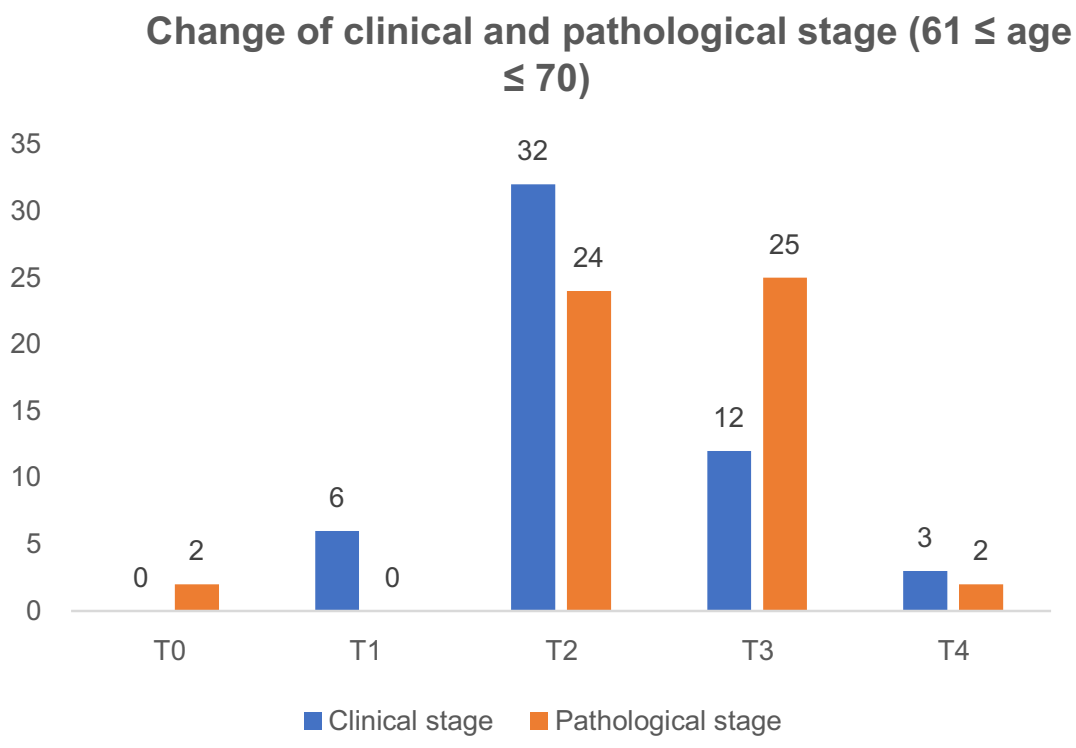

Figure 4 Change of clinical and pathological stage ( $61 \leq$ age $\leq 70$ years).

metastatic prostate cancer, hormone therapy is administered to decrease the prostate volume and inhibit tumor cell proliferation. Although the clinical stage of the tumor might appear to have decreased on imaging, the meaning of "downstaging" is not pathologically obvious. We believe that the comparison of clinical stage and pathological is also important. Unfortunately, our study did not conclude that NHT reduced pathological staging. This also needs to be further explored.

The status of postoperative urinary continence recovery was not included in our study. This is because the factors affecting urinary continence recovery are multifaceted ${ }^{10-13}$ and might include surgical techniques, the patients' own conditions, or the patients' postoperative exercise; NHT might only be one of these many factors. Therefore, assessment of urinary continence recovery should be carried out from multiple perspectives.

As ASCO-GU 2018 conference pointed out, previous studies on NHT had many defects, such as limited enrollment cases, large difference in criteria for inclusion and exclusion, and short duration of NHT. Several new therapeutic options related to NHT were proposed in the conference, such 


\section{Change of clinical and pathological stage (age > 70)}

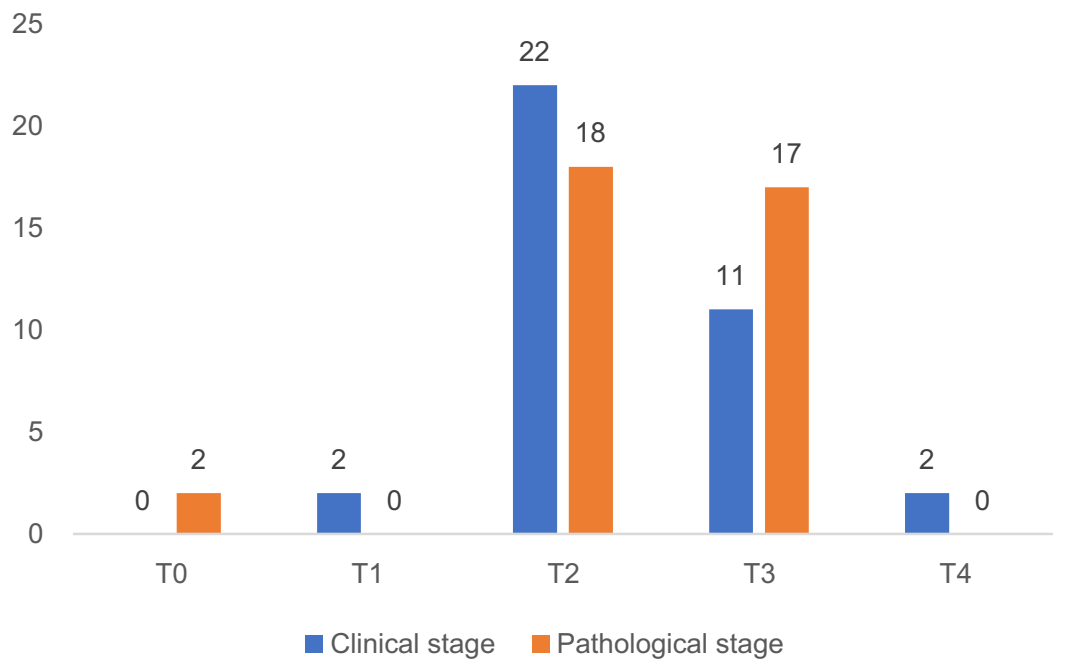

Figure 5 Change of clinical and pathological stage (age >70 years).

Table 3 Comparison between NHT group and Non-NHT group

\begin{tabular}{|c|c|c|c|c|c|c|}
\hline \multirow[t]{2}{*}{ Factors } & \multicolumn{4}{|l|}{ NHT Group } & \multirow{2}{*}{$\begin{array}{l}\text { Non-NHT } \\
\text { Group }\end{array}$} & \multirow[t]{2}{*}{$p$-value } \\
\hline & $\begin{array}{l}\text { ARA alone, } \\
\leq 3 \text { months }\end{array}$ & $\begin{array}{l}\text { Combination, } \\
\leq 3 \text { months }\end{array}$ & $\begin{array}{l}\text { Combination, } \\
\text { 3-6 months }\end{array}$ & $\begin{array}{l}\text { Combination, } \\
>6 \text { months }\end{array}$ & & \\
\hline \multirow[t]{2}{*}{ OT (min) } & I43.0 (IQR: & 95.0 (IQR: & I00.0 (IQR: & 85.0 (IQR: & I09.0 (IQR: & $0.007 \#$ \\
\hline & $108.3-182.5)$ & $71.0-132.3)$ & $65.8-129.5)$ & $66.0-111.5)$ & $71.5-181.5)$ & \\
\hline \multirow[t]{2}{*}{$\mathrm{EBL}(\mathrm{mL})$} & 50.0 (IQR: & 20.0 (IQR: & 50.0 (IQR: & 20.0 (IQR: & 70.0 (IQR: & $0.014 \#$ \\
\hline & $20.0-137.5)$ & $20.0-100.0)$ & $20.0-100.0)$ & $20.0-125.0)$ & $20.0-150.0)$ & \\
\hline PSM rate & $43.8 \%(14 / 18)$ & $26.9 \%(14 / 38)$ & $30.0 \%(6 / 14)$ & 0 & $28.8 \%(2 \mathrm{I} / 73)$ & $0.132 \%$ \\
\hline $\operatorname{LOS}(d)$ & 5.0 (IQR: $4.0-7.0$ ) & 4.0 (IQR: $4.0-5.8$ ) & 3.0 (IQR: $4.0-5.0$ ) & 3.0 (IQR: 4.0-5.0) & 5 (IQR: 4-6) & $0.046 \#$ \\
\hline $\mathrm{DD}(\mathrm{d})$ & 4.0 (IQR: 3.0-5.8) & 3.0 (IQR: 2.0-4.0) & 3.0 (IQR: 2.0-3.0) & 3.0 (IQR: 2.5-3.5) & 4 (IQR: 3-4) & $0.009 \#$ \\
\hline
\end{tabular}

Notes: \# the Kruskal-Wallis test, ※ Pearson's chi-square test.

Abbreviations: NHT, neoadjuvant hormone therapy; ARA, androgen receptor antagonists; OT, operative time; EBL, estimated blood loss; PSM, positive surgical margins; LOS, hospital length of stay; DD, drainage duration.

maximum androgen block (NHT + abiraterone + enzalutamide, or NHT + abiraterone + ARN-509), and PUNCH trial (NHT + neoadjuvant chemotherapy). The results of these clinical trials are promising.

NHT is not recommended in the current guidelines. There are two main reasons for the recommendation. One is that neoadjuvant endocrine therapy does not significantly improve the prognosis of patients with prostate cancer; the other is that endocrine therapy itself has side effects on patients, such as the impact on cardiovascular disease. ${ }^{14}$ However, clinicians in many centers still often choose this treatment for several reasons. First, great progress has been made in the development of various new hormone therapeutic drugs for NHT. The emergence of a variety of new treatment options also makes
NHT more effective in reducing the difficulty and risk of surgery. In the future, endocrine therapeutic drugs may be available to improve the prognosis and overall survival of patients with prostate cancer so that more doctors will choose NHT. Second, with the popularity of PSA screening, we also found that the numbers of patients with locally advanced or oligo-metastatic foci are also significantly higher than before. At the same time, the introduction of comprehensive treatments and precision medicine and the improvements in medical technology have also provided these patients with the opportunity to receive radical surgery. NHT plays an important role in this perspective. Effective health management is also essential for those receiving neoadjuvant endocrine therapy, which can also improve the quality of life for prostate cancer 
patients.14 Finally, in China and several other developing countries, many large hospitals treat high numbers of patients. To avoid patients waiting too long for timely treatment, many doctors chose NHT to prepare for surgery even if NHT does not improve the prognosis and overall survival.

For prostate cancer patients with oligo metastasis, NHT creates the opportunity for them to undergo radical surgery and is also the beginning for systematic treatment, which is the only way for these patients. The indicators such as overall survival and biochemical recurrence rate of these patients are also worth further exploration and research. Effective health management is also essential for those receiving neoadjuvant endocrine therapy, which can also improve the quality of life for prostate cancer patients. ${ }^{15}$

Therefore, although NHT is not recommended by current guidelines, we still apply NHT according to the individual patient and actual situation. According to the results of our study, combining the actual condition, NHT is an alternative treatment for some patients with prostate cancer, such as those with limited high-risk cancer, local progression, or oligopoly metastasis. The goal is not to improve the overall prognosis but to reduce the difficulty of surgery and improve the perioperative recovery of patients. Of course, postoperative adjuvant treatment is also essential for these patients. The patients' economic factors and the benefits of treatment should be considered when choosing appropriate treatment options.

This study has some limitations. Firstly, the retrospective nature of this study is itself an important limitation. Secondly, we did not explore the long-term benefits of our proposed treatment for prostate cancer. Thirdly, due to various objective factors, we did not compare the imaging data of patients before and after NHT.

\section{Conclusion}

NHT can reduce the OT and intraoperative hemorrhage, thus reducing the difficulty of surgery and improving the postoperative recovery of patients. However, it does not reduce the stage of prostate cancer or the PSM rate. For some specific patients, NHT is optional. We believe that NHT will improve the overall prognosis of patients as progress continues in the medical field in the future.

\section{Ethical approval}

All procedures performed in studies involving human participants were in accordance with the ethical standards of the institutional and national research committee and with the 1964 Helsinki declaration and its later amendments or comparable ethical standards.

\section{Acknowledgments}

We sincerely thank the patients for their participation in this study. This study was supported by the National key research and development program of China (Grant No. 2017YFC0908003) and Tibetian Natural Science Foundation (Grant No. XZ2017ZR-ZY019).

\section{Author contributions}

All authors contributed to data analysis, drafting or revising the article, gave final approval of the version to be published, and agree to be accountable for all aspects of the work.

\section{Disclosure}

All authors declare no competing interests in this work.

\section{References}

1. D‘Amico AV, Whittington R, Malkowicz SB, et al. Biochemical outcome after radical prostatectomy, external beam radiation therapy, or interstitial radiation therapy for clinically localized prostate cancer. JAMA. 1998;280:969-974.

2. Sanda MG, Cadeddu JA, Kirkby E, et al. Clinically localized prostate cancer: AUA/ASTRO/SUO guideline. Part II: recommended approaches and details of specific care options. J Urol. 2018;199 (3):990-997. doi:10.1016/j.juro.2018.01.002

3. Mottet N, Bellmunt J, Briers E et al. EAU-ESTRO-ESUR-SIOG guidelines on prostate cancer. Eur Assoc Urol; 2018. Available from: http://uroweb.org/guideline/prostate-cancer.

4. NCCN clinical practice guidelines in oncology prostate cancer version 4; 2018. Available from: https://www.nccn.org/professionals/phy sician_gls/pdf/prostate.pdf. Accessed February 15, 2018.

5. Schulman CC, Debruyne FM, Forster G, et al. 4-year follow-up results of a European prospective randomized study on neoadjuvant hormonal therapy prior to radical prostatectomy in T2-3N0M0 prostate cancer. Eur Urol. 2000;38:706-713. doi:10.1159/000020366

6. Soloway MS, Pareek K, Sharifi R, et al. Neoadjuvant androgen ablation before radical prostatectomy in cT2 $\mathrm{bNxMo}$ prostate cancer: 5-year results. $J$ Urol. 2002;167:112-116.

7. Aus G, Abrahamsson PA, Ahlgren G, et al. Three-month neoadjuvant hormonal therapy before radical prostatectomy: a 7-year follow-up of a randomized controlled trial. BJU Int. 2002;90:561-566.

8. Klotz LH, Goldenberg SL, Jewett MA, et al. Long-term follow-up of a randomized trial of 0 versus 3 months of neoadjuvant androgen ablation before radical prostatectomy. J Urol. 2003;170(3):791-794. doi:10.1097/01.ju.0000081404.98273.fd

9. Kumar S, Shelley M, Harrison C, et al. Neo-adjuvant and adjuvant hormone therapy for localised and locally advanced prostate cancer. Cochrane Database Syst Rev. 2006;18(4):CD006019.

10. Walsh PC, Marschke PL. Intussusception of the reconstructed bladder neck leads to earlier continence after radical prostatectomy. Urology. 2002;59(6):934-938.

11. Breda G, Celia A. How to preserve potency and continence in localized prostate cancer. BJU Int. 2007;100(Suppl 2):29-31. doi:10.1111/j.1464410X.2007.06950.x

12. Walz J, Epstein JI, Ganzer R, et al. A critical analysis of the current knowledge of surgical anatomy of the prostate related to optimization of cancer control and preservation of continence and erection in candidates for radical prostatectomy: an update. Eur Urol. 2016;70 (2):301-311. doi:10.1016/j.eururo.2016.01.026 
13. Rajih E, Meskawi M, Alenizi AM, et al. Perioperative predictors for post-prostatectomy urinary incontinence in prostate cancer patients following robotic-assisted radical prostatectomy: long-term results of a Canadian prospective cohort. Can Urol Assoc J. 2018. doi:10.5489/ cuaj.5356

14. Tucci M, Leone G, Buttigliero C, et al. Hormonal treatment and quality of life of prostate cancer patients: new evidence. Minerva Urol Nefrol. 2018;70(2):144-151. doi:10.23736/S0393-2249.17.03066-1
15. Antonelli A, Palumbo C, Veccia A, et al. Biological effect of neoadjuvant androgen-deprivation therapy assessed on specimens from radical prostatectomy: a systematic review. Minerva Urol Nefrol. 2018;70(4):370-379. doi:10.23736/S03932249.18.03022-9

\section{Publish your work in this journal}

Cancer Management and Research is an international, peer-reviewed open access journal focusing on cancer research and the optimal use of preventative and integrated treatment interventions to achieve improved outcomes, enhanced survival and quality of life for the cancer patient.
The manuscript management system is completely online and includes a very quick and fair peer-review system, which is all easy to use. Visit http://www.dovepress.com/testimonials.php to read real quotes from published authors. 